Revue des patrimoines

6 | 2005

Patrimoine en situation : l'Inventaire général entre histoire et prospective

\title{
Un nouvel arpentage urbain
}

\section{Bernard Toulier}

\section{(2) OpenEdition \\ Journals}

Édition électronique

URL : http://journals.openedition.org/insitu/2536

DOI : $10.4000 /$ insitu. 2536

ISSN : 1630-7305

Éditeur

Ministère de la culture

Référence électronique

Bernard Toulier, « Un nouvel arpentage urbain », In Situ [En ligne], 6 | 2005, mis en ligne le 20 avril 2012, consulté le 30 avril 2019. URL : http://journals.openedition.org/insitu/2536 ; DOI : 10.4000/insitu.2536

Ce document a été généré automatiquement le 30 avril 2019.

\section{(c) $(1) \Theta \Theta$}

In Situ Revues des patrimoines est mis à disposition selon les termes de la licence Creative Commons Attribution - Pas d'Utilisation Commerciale - Pas de Modification 4.0 International. 


\title{
Un nouvel arpentage urbain
}

\author{
Bernard Toulier
}

1 Prudemment laissées à l'écart durant les premières années d'activité de l'Inventaire général, les villes ont été peu à peu intégrées dans le champ d'investigation des arpenteurs de l'Inventaire. Le recul de la limite chronologique, incluant aujourd'hui le $\mathrm{XIX}^{\mathrm{e}}$ siècle et une grande partie du $\mathrm{XX}^{\mathrm{e}}$ siècle, a ouvert le préalable indispensable à ces études urbaines. A la suite de l'expérience menée par le Centre de Recherches Historiques sur l'Architecture Moderne dirigé par André Chastel sur le quartier des Halles à Paris, les études sont lancées dans les années 1970 à Tours, Angers, Rouen et Montpellier. Les outils statistiques et cartographiques permettent d'aborder la typologie des divers modes d'habiter, avec une attention particulière portée sur les relations entre foncier, parcellaire et bâti (comme ici à Briançon) et la distribution intérieure des habitations. Les études sur les hôtels bisontins du XVIII ${ }^{e}$ siècle et sur l'architecture privée de Perpignan au $\mathrm{XX}^{\mathrm{e}}$ siècle s'inscrivent dans cette perspective de recherche, renouvelant l'histoire particulière de la circulation des modèles et de la pénétration des styles.

Cependant, la ville n'est pas qu'une collection d'architectures particulières. A partir des années 1980, les approches thématiques sur les villes industrielles (exemples: Tourcoing, Sochaux-Montbéliard) ou les villes de villégiature (exemple : Hossegor, Le Vésinet) - dans lesquelles s'inscrivent les travaux sur Thiers ou Deauville - ont permis d'aborder l'analyse de l'espace urbain et d'établir les relations entre l'étude des aménagements urbains comme celles présentées sur les réseaux d'adduction d'eau de Dieppe - et les études architecturales. 
Figure 1

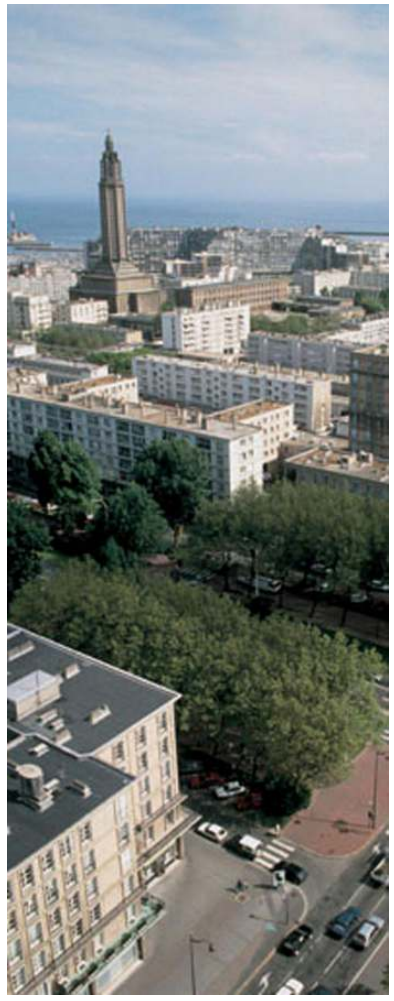

Reconstruction du Havre

Phot. Inv. D. Couchaux () Inventaire général, ADAGP, 1993

L'Inventaire possède aujourd'hui les vocabulaires, les méthodes et les outils d'investigation nécessaires à l'étude des villes. Les dernières publications sur Rennes, Le Havre (fig. $\mathbf{n}^{\circ} \mathbf{1}$ ) ou Lyon en témoignent. Ces travaux participent à la constitution d'Atlas du Patrimoine intégrés à des systèmes d'information géographique (S.I.G.), facilitant la tâche des chercheurs et les échanges de données avec les partenaires des collectivités territoriales.

\section{AUTEUR}

\section{BERNARD TOULIER}

Conservateur du patrimoine. Sous-direction de l'archéologie, de l'ethnologie, de l'inventaire et du système d'information. bernard.toulier@culture.gouv.fr 